\title{
The Comparative Study of Traditionally Female Music Education between China
}

\section{and South Korea}

\author{
Zhang Rui \\ Institute of Art of Shandong University(Weihai) \\ ,doctor,lecture.
}

\begin{abstract}
:
Since half a year, the female music education has developed by leaps and bounds. However, compared with the counterpart in South Korea, there are still some differences, which is exactly the essential differences in music education. Based on the discussion about the dominance and importance of female music education, this text compared and analysed the traditional music education to the female in twenty century between China and South Korea through three aspects, including educational background, professional education, and educational methods.
\end{abstract}

\section{KEY WORDS:}

Chinese and South Korean women, music education, comparative study, twenty century.

\section{INTRODUCTION}

\subsection{The Dominance of Female Music Education}

Firstly, psychological dominance. The experiment named split brain did by the American psychobiologist Roger Wolcott Sperry confirmed the method that "division of labor between left and right head ", which proved that the left heads of people are mainly occupied in logical thinking, while the right brain is occupied in imaginal thinking and the pivot of the learn of art and experience. Men use their brain in the way of the different labors of

\author{
Ji Huihui \\ Institute of Art of Shandong University(Weihai) \\ ,master,lecture
}

right and left one, however the women can use their left and right brains simultaneously. Therefore, the women have more naturally physiological dominance in receiving art education than men do, such as music. When learning music, we need to use hands and brains simultaneously,and sometimes pay attention to the breadth as well, which reflects the demand of the ability of coordinate exercise and control among every part of human body while learning music. A neurologist of University of California confirmed that women have $30 \%$ more connecting points of brains than men do, and the more connecting points of brain one has, the better his or her coordinate ability is. Therefore, compared with the men who have less connecting points, women will do slightly better in music learning. Secondly, psychological dominance. Women usually use right brain more, which is also called image brain. It can totally transform what one heard and thought into picturesque understanding and abundant images, which is essential in musical composition, performance and appreciation. The outstanding features of psychology of those women who have neural excitability is that women are more rich in emotion than men do, and can express their feelings about the understanding and expression of the emotion in music through abundant imagination and exquisite emotion. Compared with men, women are more quiet and restraining; 
therefore,they're more suitable for the bald music learning. Since childhood, girls are more well-behaviored than boys and more persistent in the music courses arranged by parents .It's women's persistence and profound understanding that make them have the unique dominance in music learning.

\subsection{The Importance of Female Music Education}

The learning and appreciation of music can train and enhance people's ability of hearing, memory, appreciation, aesthetic, coordinated control, imagination and creativity. Meanwhile,music also has the function of emotion and mental regulations, which are good for the cultivation and improvement for comprehensive self-quality, which is also the improvement for comprehensive self-quality of the women who occupy half of the gross population.In recent years, Education department in China vigorously advocates quality-oriented education, and make efforts to cultivate high-competent and comprehensive talents who are all-round development of morality, intelligence, physique and aesthetic .Music education is not only an important part of school education, but also an important means of the realization of quality-orientd education. One of the significant characters in current music education is that the majority are women, especially all levels of education system in China .Therefore, to enhance female music education in China can not only enhance the comprehensive qualities of music teachers and accelerate the development of quality-orientd education in the context of school, but also prompt the developmental level of Chinese educational business in the future. The vast majority of family education, which is the initial education form of human falls to the women. The women who have received systematic music education can combine with their own experience during the process of the education to their children;direct and cultivate their children according to the characteristics of their physical and mental development;prompt their mental and physical department, and lay a good foundation for their multiple intelligence and healthy personality as well.

\section{The comparison of the background of traditional music education between China and South Korea \\ 2.1The Comparison of Cultural Background}

The Confucian culture has long been deep-rooted in families and society .Not until modern times were the women in China and South Korea discriminated only for their female gender. They could not enjoy the same human rights as the boys did from childhood; were deprived the personal library and forced to be faithful to the feminine duty; and were regarded as rabbles and had no courteous reception and position for lake of education. With the popularization of school education and the influence of Western Europe in modern ages, women have the opportunity to receive general education as men do. And with the help of the female liberation movement in South Korea in 1960s, now female talents are making great efforts and contributing a lot to every field of society .Also, South Korea is regarded as one of the countries which have the most female composers .

\subsection{The Comparison of Social Background}

Since the reform and opening-up ,the politics and social order are relatively stable, and the sustainable development of economic, culture, education rise sharply. At the same time, the number of female students who major in composition and graduated from domestic music schools increases every year. However,there are few of them rather than not 
many of them become real composers when they are out schools and in society. In China, a country with 1.3 billion people,the cultivation of professional female composers in the music creation field which needs opening and creative thinking is not ideal, which can't be regarded as the malpractice of Chinese education system. With a view to "Chinese and South Korean music education and women", compare the education system to explore the malpractices. Take the growing process and achievement of the typical female composers as example, find out the root of difference between China and South Korea;outlook the development of music education; and provide conditions to their emergence in creation field. Artistic creation is a creation activity in which the artists use the means of artistic image to present their feeling of life and make people feel and appreciate. Artists are those who make self-seeking legalisation and combine work production into the infinite desire to self-transcendence.

\section{The Comparison of Women's Professional Music Education in China and South Korea in Modern Ages}

All the art activities including composition, especially the composition of music, which to a great extent, reflects on the skillful control and usage, need education, training, and long-time practice .The systematicness and leakproofness of composing technique is extremely complex and untouchable for any other arts. The training of systematic composition is the basic of music composition. The man who works on music composition need a long-time systematic professional education. For an instance, most of the composers around the world like Mozart and Beethoven received systematic and profound music education when they were young. Except those female composers like Clara, who received systematic music education from a family of music, the well-known female composers in West have one common ground, that is they are all nobles, which is an accidental phenomenon with inevitability.

The reason why women in China and South Korean didn't make any notable achievement until modern times is that people are constrained outdated by the gender consciousness in the same cultural circle of Confucianism .The school education was popularized after modern times, and the equality of men and women in education is formulated and put into effect by the state, which changed women's consciousness greatly, guaranteed the human rights of women and promoted the emergence of professional women in every field, and the professional music education of women has also developed by leaps and bounds as well. With the gradual extinction of the defiance and prejudice of female creativity, the female enrollment of musical universities has a substantial increase since 1980s .The female composers, who are celebrated at home and abroad, such as Piao Yingji and Chen Enshu in South Korea and Li Yiding and Gong Xiaoting in China, are all educated by systematic professional education .Particularly, most of the successful female composers not only received professional education at home, but learned modern composition techniques abroad. However, after making a survey of the successful examples of the female composers who are celebrated in South Korean composition field, it's not difficult for us to see that the root of female problems is not how much professional music education they have received. It's their consistent passion, perseverance, and complete devotion that makes us sign with emotion and arouses the speculation of the root of perseverance and 
courage.

\section{The Comparison of Family and School Education to Women between China and South Korea}

\subsection{The Comparison of Family Education}

Family education is an education activity done by parents and elders to their children and younger generation in family life. The social knowledge, moral rule, social behavior,and sexual canalization of children are first acquired from family, and the social value and goals are also imparted by parents. The environment of family education, which includes the educational conception, standard of culture and educational methods of patriarches, and the expectation to their children, ect,directly influenced children's health, mental and physical. Therefore, a favorable family environment is the basic for children to give full play to their enthusiasm, initiative, and creativity. In the past, like China, the family education in South Korea were mainly standard of behavior which fit for gender roles of people .However, now influenced by western civilization, with the gradual spread of equality of men and women and self-awareness are, the differences between men and women and the importance of gender roles also diminished. On the contrary, patriarches pay more attention to children's potential rather than their genders. It's easy to see the concern level of patriarches and upsurge of potential development from the generalization of family art education in South Korea. According to an investigation, patriarches in South Korea pay more attention to the personality cultivation and emotional education, while patriarches in China take more care of school record and enrolment rate. According to an investigation based on genders, the patriarches in South Korea tend to cultivate the self-independent ability and subjective consciousness of girls. Compared with patriarches of South Korea, the counterpart of China pay attention to the intelligence development of children. Although they take care of children's life, they pay insufficient attention to the education of characteristics and behaviors. We can hardly see the scene that parents take bags for their children on the street in South Korea, and they take bags respectively. However, in China, the circumstance that parents gather up sundries for children at school gate after school can be find everywhere. There are great differences, which reflect the the content and means in family education between China and South Korea in the cultivation of independence and perseverance.

Take the out-of-class piano education for example,most patriarches in China are not clear about the goal and meaning of art education .The parents in South Korea take the interest-oriented and process-oriented view of education.However, for lake of knowing the importance of process, parents in China are more likely to force children and often lead to frustration halfway. The family music education in South Korea pays more attention to the enlightening education method rather than skill training. Putting the goals of music education on expansion of perseverance and imagination, it's quite common and easy for us to get interested in masterpieces, rhymes and composition. The children in China are strictly supervised by parents during exercise, while the parents in South Korea guide their children exercise consciously. The typical family structure in South Korea is that husbands take charge of livelihood, and wives take charge of children's education. Although the increasing number of working couples changes the traditional family structure in some way, it still plays a germane role in children's growth and the generation of 
characteristics that mothers take care of and support children devotedly. It can increase children's self-confidence, and play a positive role in the development of children's characteristics that often communicate with children, and say something encouraging, such as "You can do it." and "Well done."

Self-confidence is the key factor of success, without whose support, a man can't be an independent and innovative talent. The general goal of family education in South Korea is to make children feel self-compliment, confident, and have a sense of achievement by continuous encouragement, and to know that success comes from efforts .The fierce competition between parents can positively push forward the growing process of children. After reform and opening-up and with the development of market economy, people's living standard in China has increased greatly .Because the importance of quality-oriented education enhanced increasingly, more parents choose to give their children extra art and music education. And to response the family planning policy, more nuclear family emerged,who care about children's education more than ever before. However, it may go against cultivating children's toughness, confidence and emulation that follow other parents whatever they do instead of laying down the goal of education on developing what children are interested in. The lack of music learning objectives results in the lack of confidence and endurance, and the lack of attention to personality cultivation results in the lack of desire to show off. It shows their unsubstantial subject consciousness that students who are going into society can't give full play to what they've learned to pave the way for themselves. And the phenomenon that they tend to choose easeful job also reflects their lack of spirit of challenge and adaptive capacity to society. The family construct of working couple is dominant in China. Parents are busy in working, so the children can't be taken care of well during their character formation period.

\subsection{The Comparison of School Education}

School education is an special education activity that purposefully, designedly, organisedly, and systematically impart students knowledge and skill; cultivate ideology and morality; develop intelligence and enhance physical strength. In modern society, with the comprehensive popularization of education, school becomes teenagers' second life space, plays an important role in the generation of genders, and is an important base to perform the socialized function. The syllabus of primary school in South Korea is different from that in China. All the courses are arranged in the morning, and according to children's own need, they can receive abundant out-of-class cultural knowledge in different "institutes" in the afternoon. There are required courses and optional courses in high school, and students can study according to their hobbies and interests .Although there are some gender differences in the setting of curriculum, on the other hand, it provides convenience to the students of different sexual in choosing what they like. On the contrary, no matter boys or girls, the setting of curriculum in China from primary school to high school are the same. And most of them are required courses, few are optional courses. The sexual differences don't sufficiently reflect in the setting of courses. And the curriculums span from morning to afternoon, which obviously means a scramble to those who study music or other out-of-school courses. Most often, the lack of gender consciousness of teachers may leads to their prejudice to students, and naturally the vision and behavior of students can also be influenced. 
The "injection type" of education, which is dominant by teachers, is the complete picture of the traditional education in China. On the contrary, South Korea adopts more democratic and equal relations between teachers and students .The authoritative education pattern is quite rare, and students can declare their ideas in class unconstrainedly. The structure of rights exists in school education is the inherent malady exists in the development process of Chinese history .China was influenced by the thought of extreme left and right for a long time, and people's spirit and consciousness are constrained. Especially during the ten years of the Great Culture Revolution, people lost freedom of expression under the closed circumstance, and their personalities were despised. Also, the intellectuals had trouble in guaranteeing the freedom of learning ; updating the structure of knowledge ;expressing initiative ideas flexibly; receiving new things positively; and having enough critical consciousness .On the contrary, in capitalist society, with the development of material civilization, liberalization of expression, and diversification of narration, the consciousness and thinking model become more open and self-centered. After modern ages, South Korea became the colony of the US for continuous defeat in national liberation movement, and due to the influence of democratic politics and western culture,the cultural environment became more open. Generally speaking, the education in democratic politics is not unlimited, but infinitely open. The functions of education in democratic politics are liberation of spirit and increase of critical ability.The "femaleology curriculum "developed by South Korean University aroused women from the sexual differences of traditional culture, established the subjectivity and autonomous rights of women, and gave women the sense of competition and social consciousness.

\section{Conclusion:}

The subject consciousness is a right and ability enjoyed by people and exercised under independent thinking and understanding, and it's a conscious activity with teleonomy. It's often established, developed, and enhanced in the form of "education" through the process of perfecting humanity. With the continuous accumulation and expansion of knowledge by education, the consciousness of self-improvement and challenge, which is the requirement of individuals to become members of society,also increased. Therefore, women's traditional music education plays a significant role in the development process of music education.

\section{References:}

[1] Zhou Yongqin. Summary of the Study of Chinese Women's Musical Culture [J].Popular Literature . 2011(07)

[2]Gong Chunting. The Factors of Cultural Thoughts that Influence Verbal Behaviors of South Koreans_— Taking the Thought of "Inferior and Superior" as Example[J]. Knowledge Economy. 2010(18)

[3] Chen Jing. The Pioneer of Chinese Women's Music Education in Modern Times - the Study of Music Education in Chinese and Western Women's Private School in Shanghai.(1917-1930)[J]. Journal of Central Conservatory of Music. 2010(04)

[4] Xie XIaojing. The Trial Analysis of the Formation of Feminist Consciousness and Social Environment in Popular Music in New Period[J]. Chinese Musicology. 2007(01) 